\title{
El triunfo del experimentador dativo: Las colocaciones con "entrar + nombre de estado" en diacronía
}

\author{
The triumph of dative experiencers: \\ "entrar + state noun" collocations in diachrony
}

Josep Alba-Salas

College of the Holy Cross (Massachusetts, EE.UU.)

jalba@holycross.edu

RESUMEN: Se examina la evolución histórica de tres tipos de colocaciones formadas con entrar y sustantivos de estado: con experimentador dativo (p. ej. le entró temor), con experimentador sujeto (p. ej. el caballero entró en temor), y con experimentador locativo (p. ej. entró temor en él). El esquema locativo, que predominó inicialmente, fue eclipsado por la estructura con sujeto en el XVII, pero desde el XIX predominan los dativos. Esta evolución responde a otros cambios más generales en el español, especialmente el triunfo del experimentador dativo en las construcciones que designan procesos físicos o mentales involuntarios.

Palabras clave: colocación, entrar, sustantivo de estado, experimentador, dativo, estudio diacrónico.

ABSTRACT: This study examines the historical evolution of three types of Spanish collocations formed with entrar and state nouns: with dative experiencers (e.g. le entró temor), with subject experiencers (e.g. el caballero entró en temor), and with locative experiencers (e.g. entró temor en él). The locative construction, which predominated initially, was eclipsed by the subject structure in the $1600 \mathrm{~s}$, but datives prevail since the 1800s. This evolution follows from other, more general changes in Spanish, particularly the victory of dative experiencers in constructions indicating involuntary physical or mental processes.

Keywords: collocation, entrar, state noun, experiencer, dative, diachronic study. 


\section{LAS ESTRUCTURAS ESTUDIADAS Y SU INTERÉS HISTÓRICO}

En sus usos rectos, el verbo entrar designa "un desplazamiento que se efectúa desde el exterior al interior de algún objeto o lugar" y aparece con un complemento locativo introducido por la preposición en o a (Morimoto, 2001: 53) ${ }^{1}$. Al igual que otros verbos de movimiento, entrar ha recibido bastante atención en varios estudios recientes dentro de la semántica cognitiva (Barrajón López, 2006: 465-800; Eslava Heredia, 2012; Ibarretxe-Antuñano, 2003; Morimoto, 2001: 63-112 y Paz Afonso, 2013, 2015). Dichos estudios han explorado no solo el sentido recto de entrar ${ }^{2}$, sino también usos figurados o nocionales del tipo entrar en batalla, entrar en crisis o entrarle hambre, que suelen analizarse como extensiones metafóricas o metonímicas basadas en la idea básica de movimiento ${ }^{3}$.

1 Esta alternancia preposicional se documenta ya desde el XIII (Paz Afonso, 2013: 317). Como subraya Eslava Heredia (2012: 425), en la bibliografía se suele asumir que (a) la preposición en se prefiere en España, mientras que $a$ es más frecuente en Latinoamérica, y (b) entre los hablantes peninsulares, la alternancia conlleva matices semánticos diferentes: entrar en enfatiza el término o punto final del movimiento (una ubicación interna); entrar a focaliza la dirección o trayectoria (véanse, entre otros: Eslava Heredia, 2012: 426-430; Ibarretxe-Antuñano, 2003; Morimoto, 2001: 86-108 y las referencias allí citadas). A partir de datos de corpus de España, Argentina, Venezuela y México, Eslava Heredia (2012) matiza ambas generalizaciones al concluir no solo que "la preposición $a$ no es la preferida en términos cuantitativos para las normas americanas" (430), sino también que el contraste semántico asociado con la alternancia preposicional se extiende al español mexicano, por lo que "debería considerarse una estrategia cognitiva-semántica más general de la lengua española" (446).

${ }^{2}$ En una de las propuestas más influyentes, Morimoto (2001) — siguiendo a Talmy— analiza entrar y otros verbos de desplazamiento como predicados que lexicalizan o fusionan dos componentes semánticos: Desplazamiento (el de un objeto o Figura que se mueve o está ubicado con respecto a un objeto de referencia o Fondo) y Trayectoria (el curso que sigue la Figura con respecto al Fondo) (51-53). Morimoto formaliza este análisis dentro de la Semántica Conceptual de Jackendoff, y propone que entrar muestra dos estructuras argumentales porque permite dos posibilidades de correspondencia del componente de Trayectoria en su Estructura Léxico-Conceptual: una (entrar en) en la que el argumento espacial es un complemento de ubicación, y otra (entrar a) en la que dicho argumento es un complemento de destino (94-108).

${ }^{3}$ Por ejemplo, Paz Afonso (2013) propone que entrar en es compatible con sustantivos eventivos como batalla porque "todo evento, además de tener una duración concreta, ocurre en un espacio determinado" (320), por lo que puede reinterpretarse como un lugar físico por metonimia (321). Por su parte, Barrajón López (2006) sostiene que entrar en puede aparecer con sustantivos de estado (p.ej. crisis) a través de una metáfora que conceptualiza los estados como recipientes (lugares físicos a los que dotamos de una orientación dentro-fuera), de manera que un cambio de estado se concibe como un cambio de localización (773). En casos como entrarle hambre (a alguien), Barrajón López todavía observa "un sentido de desplazamiento y cierta locatividad al concebir como lugares abstractos" las sensaciones designadas por el sustantivo que aparece como argumento interno de entrar, pero "en estos casos el desplazamiento es prácticamente imperceptible", por lo que "entrar sufre un cambio de significado importante" (639) y el complemento dativo no se interpreta como una ubicación, sino como "una "entidad afectada" que experimenta el proceso verbal" (641). 
El presente trabajo examina la evolución histórica de ciertos usos nocionales de entrar, a saber, las estructuras formadas con sustantivos que denotan estados físicos (p. ej. frío, sed, sueño) o sicológicos (p. ej. duda, miedo, ganas, rabia). Dichas estructuras son colocaciones en el sentido de Alonso Ramos (2004: 20-21), esto es, combinaciones léxicamente restringidas de dos unidades léxicas: una que el hablante escoge libremente para expresar sus necesidades comunicativas (la base de la colocación), y otra (el colocativo) seleccionada de forma parcialmente arbitraria en función de la base para expresar un sentido particular (cfr. Bosque, 2001: 15-20) ${ }^{4}$.

Como veremos más adelante, históricamente estas colocaciones se han asociado con diferentes esquemas sintácticos. En el esquema que ha prevalecido en el español moderno, el sustantivo de estado sirve como sujeto gramatical de entrar, controlando la concordancia verbal. Por otra parte, la entidad que experimenta el estado designado por dicho sustantivo (el experimentador, en la terminología clásica de los roles semánticos) se realiza como objeto indirecto. Concretamente, el experimentador se realiza como un clítico dativo que puede aparecer también (de forma opcional) con un sintagma correferente introducido por la preposición $a$, p. ej. (a los niños) les entró miedo. Estas estructuras (en adelante entrarle $N$ ) se ilustran a continuación con ejemplos obtenidos del Corpus del español (Davies, 2002), cuyas características se discuten en la sección $2^{5}$.

(1) Fue entonces cuando me entró la duda de haber visto o haber recordado un rato antes a mi amigo Veblen. (El lado de la sombra, Adolfo Bioy Casares, 1991)

(2) [...] o la mamá, les leyera [...], para que les fuera entrando el amor y la curiosidad... por la lectura, porque [...]. (Habla Culta de Caracas (Venezuela): M26)

(3) Cuando mi padre pasaba un tiempo fuera de su casa le entraba una inmensa angustia, y se volvía intolerante. (El nombre prestado, Susana Gertopan, 1997)

(4) Podría describir las ganas que le entraron a él de arrojarse al agua, dejarse llevar por la corriente y [...]. (Que si el sol estaba alto, Mauricio León Valle, ca. 1997)

\footnotetext{
${ }^{4}$ Las colocaciones se distinguen de otros dos tipos de estructuras: los sintagmas libres (p. ej. entró en/a la casa), donde un predicado selecciona a sus argumentos atendiendo únicamente a sus propiedades semánticas y/o aspectuales; y las expresiones fraseológicas (p. ej. estirar la pata), que - a diferencia de las colocaciones - carecen de composicionalidad semántica y típicamente impiden operaciones sintácticas como el movimiento, la modificación o la relativización del sustantivo que aparece en posición de objeto (Alonso Ramos, 2004: 40-48).

${ }^{5}$ Obsérvese que el sustantivo de estado goza de autonomía sintáctica con respecto a entrar, ya que puede coordinarse con otros nombres de estado, (2) y (5), modificarse con adjetivos y cuantificadores, (3) y (5), y relativizarse, (4), entre otras operaciones sintácticas (cfr. nota 4).
} 
(5) Pero cuando vi la cantidad que era me entró un nerviosismo y un miedo espantoso a perderlo o a que me lo robaran. (Paredes, un campesino extremeño, Patricio Chamizo, 1974)

Como señalan varias fuentes lexicográficas (véase entrar en el DRAE, el DUE de Moliner y el Diccionario del español actual o DEA), las colocaciones tipo entrarle $N$ tienen el sentido incoativo de 'empezar a dejarse sentir' el estado designado por el sustantivo que se combina con entrar. Estas estructuras, pues, son versiones incoativas de las Construcciones con Verbo de Apoyo (CVA) formadas con el verbo tener más los correspondientes nombres de estado (cfr. Alonso Ramos, 2004: 108; Barrajón López, 2006: 641 y Gross, 1981: $33)^{6}$. Así, por ejemplo, a Miguel le entra un miedo espantoso es una versión incoativa de Miguel tiene un miedo espantoso, de ahí que podamos parafrasear informalmente la colocación con entrar como 'Miguel empieza a tener un miedo espantoso'. En este sentido, y siguiendo la terminología de Alonso Ramos (2004: 108), las estructuras tipo entrarle miedo son colocaciones fasales en las que el sustantivo predicativo - la base de la colocación- selecciona léxicamente a entrar —el colocativo - para indicar el momento en que se empieza a experimentar el estado físico o sicológico designado ${ }^{7}$.

En el español moderno entrar también aparece con ciertos sustantivos de

\footnotetext{
${ }^{6}$ Como es bien sabido, en las CVA el elemento que determina fundamentalmente el contenido semántico e introduce los diferentes complementos no es el verbo, sino el sustantivo predicativo que aparece con él; esto lo demuestra el hecho de que dicho sustantivo puede aparecer en una nominalización con los mismos complementos que en la CVA, pero sin el verbo (Cattell, 1984: 2; Jespersen, 1942: 117). Aunque el análisis de estas estructuras y la terminología utilizada difieren según el enfoque teórico y la tradición linguiística, las distintas propuestas coinciden en que el verbo que aparece en la CVA tiene como función principal expresar el tiempo, modo y persona y proporcionar las posiciones sintácticas donde se realizan oracionalmente el sustantivo predicativo y sus complementos; para una panorámica reciente de las principales propuestas tanto en español como en otras lenguas, véanse, entre otros, (Alba-Salas, 2002: 1-4, 60-106; Alonso Ramos, 2004: 17-31; Bustos Plaza, 2005: 20-76; Mendívil Giró, 1999: 89-124; Piera y Varela, 1999: 4415-4418, y las referencias allí citadas).

${ }^{7} \mathrm{El}$ valor fasal de entrar en las colocaciones tipo entrarle miedo encuentra una explicación natural dentro de la perspectiva cognitivista en la que se enmarcan los estudios más recientes sobre este verbo, una perspectiva donde "el esquema conceptual [...] propio del desplazamiento espacial sirve también para representar cambios o transiciones más abstractos, como es el cambio de estado" (Morimoto, 2001: 204, cfr. Talmy, 2000: 40; véanse las notas 2 y 3). Como señala un evaluador anónimo, al ser un verbo de movimiento inherente, entrar se relaciona con la idea de acceso a un espacio, lo cual facilita su uso para indicar el punto inicial de un cambio de estado. Al igual que este evaluador externo, Barrajón López (2006: 641) y Cifuentes Honrubia y Llopis Ganga (1996: 14-15, 103-107) destacan la continuidad básica entre el sentido físico de entrar y su uso como 'empezar a tener' en las colocaciones tipo entrarle miedo. Según estos investigadores, existe una vinculación muy estrecha entre localización y posesión. Si uno siente una sensación física o mental, es porque dicha sensación existe y puede localizarse en un experimentador, de manera que "cuando uno experimenta este tipo de sensaciones automáticamente se convierte en poseedor de todas ellas” (Barrajón López, 2006: 641).
} 
estado en otro tipo de estructura donde el experimentador es el sujeto gramatical y el nombre predicativo va introducido por la preposición en. Esta construcción (en adelante, entrar en $N$ ) se ilustra en los ejemplos (6) y (7), obtenidos también del Corpus del español.

(6) La flaca Nancy salía algunas veces con él [...], y Javier concebía entonces grandes esperanzas y entraba en estado de euforia. (La tía Julia y el escribidor, Mario Vargas Llosa, 1977)

(7) La nena estaba bastante mejor cuando la dejamos, pero doce horas después entró en coma. (Síndrome, Mabel Pedrozo Cibilis, 1996)

Al igual que las construcciones tipo entrarle $N$, las estructuras tipo entrar en $N$ también son colocaciones incoativas. Sin embargo, entrar en $N$ no corresponde a una CVA con tener (cfr. *la niña tenía coma), sino a una CVA con estar. Por ejemplo, la nena entra en coma es una versión incoativa de la nena está en coma, de ahí que podamos parafrasearla como 'la nena empieza a estar en coma' ${ }^{8}$. El hecho de que en la CVA con estar el sustantivo de estado aparezca también en un sintagma preposicional indica que, a diferencia de las estructuras tipo entrarle $N$, en las estructuras tipo entrar en $N$ no tenemos una colocación, sino dos: una formada por el sustantivo de estado (la base) y la preposición en (el colocativo); y otra colocación más grande donde este sintagma preposicional sirve de base y selecciona a entrar como colocativo 9 .

En el español de hoy, estos dos tipos de construcciones con entrar (entrarle $N$ y entrar en $N$ ) suelen estar asociados con diferentes clases de sustantivos.

\footnotetext{
${ }^{8}$ La observación de que la colocaciones tipo entrar en $N$ están asociadas con las CVA tipo estar en $N$ es consistente con la propuesta de Jackendoff de que existe una relación de implicación o inferencia entre el desplazamiento de tipo télico (el que indica entrar) y la ubicación resultativa, de manera que al final de un evento en el que ' $\mathrm{X}$ se desplaza a lo largo de una trayectoria que culmina en Y' (el sentido básico de entrar), el resultado es que 'X está en Y' (Morimoto, 2001: 192; cfr. notas 2, 3 y 7).

${ }^{9}$ En las colocaciones tipo entrar en $N$ el sustantivo de estado solo tiene autonomía sintáctica si es compatible con un artículo indefinido (cfr. Giry-Schneider 1987: 33-34). Así, entrar en coma (donde el sustantivo puede aparecer con un artículo indefinido en ciertos contextos) puede modificarse con determinantes y adjetivos (p. ej. entró en un coma profundo), coordinarse (p. ej. entró en coma y (un) estado de shock anafiláctico) y relativizarse (p. ej. el coma profundo en el que entró). En contraste, entrar en calor (donde el nombre no admite un artículo indefinido bajo ninguna circunstancia) calor no puede modificarse (*entró en mucho/gran calor, *entró en [un] calor endiablado/ dulce) ni relativizarse (*el calor en el que entró), aunque sí puede separarse del verbo (p. ej. entró un poco en calor). Aún así, entrar en calor comparte dos propiedades esenciales de las colocaciones tipo entrar en $N$ : a diferencia de las expresiones idiomáticas (cfr. nota 4), es semánticamente transparente (de ahí que, por ejemplo, el DEA y el DRAE definan entrar en calor como 'empezar a sentirlo', s. v. calor); y, en ciertas variedades del español (aunque no en todas), todavía está asociada con la CVA estar en calor, que se ilustra en (i).

(i) Bueno aquí el frío jamás cesará [...], pero para estar en calor unas buenas cervezas y buena música te alivianan de maravilla. [http://www.hearingthevoice.com/blog/ interviews/dbses]
} 
Según el REDES (Bosque, 2004: 944-945, s. v. entrar), las estructuras tipo entrarle $N$ se forman con sustantivos que expresan "reacciones físicas a alguna cosa, a veces reinterpretadas como anímicas" (mareo, calor, fiebre, dolor, tos, sudor), "movimientos compulsivos" (escalofríos, temblor, convulsión, tembleque, taquicardia, palpitaciones, calambre), "síntomas de alguna necesidad corporal" (sueño, somnolencia, modorra, sed, hambre, apetito) y "los sustantivos sensación, sentimiento y ataque, que a su vez admiten muy diversos complementos nominales" (sensación de felicidad, ataque de locura). Además, en el tipo entrarle $N$ también encontramos "sustantivos que denotan deseo o necesidad anímica con diversos grados de intensidad o vehemencia" (gana, deseo, impulso, tentación, prisa, mono, afición, obsesión), "sustantivos que denotan aflicciones caracterizadas por la falta de ánimo, de inquietud, de voluntad o de dinamismo" (tristeza, pena, desazón, morriña, nostalgia), "sustantivos que denotan falta de fuerza, atención, disposición o interés por las cosas" (cansancio, fatiga, agotamiento, pereza, aburrimiento, flojera, debilidad), "sustantivos que designan la risa, el llanto y otras manifestaciones expansivas emocionales de naturaleza física, frecuentemente negativas, aunque no en todos los casos" (risa, rabia, cabreo, llantina, llorera, soponcio, berrinche), "sustantivos que denotan temor" (miedo, pavor, terror, pánico), y "sustantivos que expresan incertidumbre o preocupación" o "ciertos movimientos compulsivos internos que, usados figuradamente, denotan inquietud, interés o curiosidad" (duda, gusanillo, cosquilleo, sospecha, vacilación). Por otra parte, en las estructuras tipo entrar en $N$ del español moderno encontramos sustantivos de estado tales como coma, estado (de), letargo y situación (Bosque, 2004: 944), así como agonía, aprensión, calor, cuidado, curiosidad, deseo, esperanza, éxtasis, perplejidad, recelo y tentación (véase entrar en el $D E A$, el $D R A E$ y el $D U E$ ). A esta lista también habría que añadir cólera, desasosiego, furor, ira, sospecha y sueño, que se documentan en el Corpus del español en textos recientes, p.ej. (8)-(10) ${ }^{10}$.

(8) [...] cuando conoció el comunicado del gobierno de Estados Unidos [...], el coronel Gallego entró en ira santa. ("Cómo arar en el mar", noticiero Semana.com [Colombia], 1997)

(9) [...] un ceceo, una vacilación en las vocales o en las consonantes; un tono gutural o hueco; unos bigotes así, un pelo acá, lo hacían entrar en sospechas. (Hijo de ladrón, Manuel Rojas, 1951)

\footnotetext{
10 Además de sustantivos de estado, las estructuras tipo entrar en $N$ también admiten otros tipos de nombres, incluyendo aspecto, asunto, cuestión, forma, materia y tema, nombres que expresan situaciones conflictivas (batalla, controversia, debate, discusión, guerra, lucha, pelea, polémica), y sustantivos como acción, contacto, relación, y servicio, entre otros (Bosque, 2004: 944; para un estudio diacrónico de las expresiones del tipo entrar en batalla, véase Paz Afonso, 2013). A diferencia de los nombres de estado, ninguno de estos otros sustantivos puede aparecer en las colocaciones tipo entrarle $N$ (cfr. *entrarle un aspecto/guerra/contacto), y por tanto se excluyen de la discusión que sigue (pero véase la sección 4).
} 
(10) La víctima de un envenenamiento agudo por barbitúricos experimenta agitación y náuseas, o entra en un sueño profundo marcado por una respiración [...]. ("Veneno", enciclopedia Encarta, 1997)

En el español moderno, pues, algunos sustantivos de estado solo aparecen en la estructura entrarle $N$ (cfr. *entrar en cansancio/hambre), mientras que otros están confinados al esquema entrar en $N$ (cfr. *le entró [un] coma). Sin embargo, ciertos nombres (p. ej. calor, cólera, recelo, sospecha y sueño) son compatibles en mayor o menor grado con ambas estructuras, como puede constatarse en el Corpus de Referencia del Español Actual o CREA.

El hecho de que ciertos nombres que aparecen en la estructura entrarle $N$ también sean compatibles con el esquema entrar en $N$ nos invita a preguntarnos cómo ha cambiado históricamente la distribución de tales nombres en estas dos construcciones y, más concretamente, si en periodos anteriores de la lengua había más sustantivos de estado que aparecieran en la construcción entrar en $N$. Hasta el momento, se trata de una pregunta sin respuesta, ya que ningún estudio diacrónico sobre las colocaciones del español (Alba-Salas, 2007, 2009, 2012a, 2012b, 2013a, 2013b; Alonso Calvo, 2009; Beas Teruel, 2009; Blanco, 1995 y Dubský, 1962, 1965) se ha centrado específicamente en las estructuras con entrar ${ }^{11}$.

Pese a la falta de estudios específicos, encontramos referencias ocasionales a las estructuras que nos ocupan en varios estudios diacrónicos sobre entrar. Por ejemplo, Paz Afonso (2015: 1552-1556) indica que las estructuras tipo entrarle calentura (un uso que, al igual que otros investigadores, considera una variante del sentido recto de entrar; cfr. notas 3 y 7), se documenta solo a partir del XIII. Esta situación contrasta con la de otros usos figurados de entrar (p.ej. entrar en folgura y entrar en batalla), que se documentan antes (cfr. nota 10). Por otra parte, el Diccionario de construcción y régimen o DCR (s. v. entrar) incluye tres ejemplos históricos que documentan los dos tipos de colocaciones con entrar en el Siglo de Oro: uno de entrarle $N(11)$, y dos de entrar en $N$, (12) y (13). El ejemplo de entrar en esperanzas en (13) resulta particularmente interesante porque, como podemos constatar en el CREA, hoy en día esperanza aparece también en la construcción entrarle $N$.

(11) Entróme, que non debiera, / El cansancio (;Oh montañas de Galicia!, Luis de Góngora, 1609)

(12) Habiendo [...] pronunciado estos versos, todos los circunstantes entraron en gran perplejidad. (Historia etiópica de los amores de Teágenes y Cariclea 2, trad. Fernando de Mena, 1587)

\footnotetext{
${ }^{11}$ Lo mismo puede decirse de los estudios diacrónicos sobre el equivalente de entrar en otras lenguas románicas (Chacoto, 1998; Chaurand, 1983; De Marco, 1995; La Fauci, 1979 y Marcello-Nizia, 1996).
} 
(13) Entraban en esperanzas de mejor fortuna, prometiéndose grandes progresos de tan favorables principios. (Historia de la conquista de México, población y progresos de la América septentrional, o Nueva España 2.2, Antonio de Solís y Rivadeneyra, 1684)

El DCR (628, s. v. entrar) también documenta miedo, pánico y tristeza (tres sustantivos que hoy en día aparecen en las colocaciones con experimentador dativo) en un tercer tipo de construcciones con entrar. Se trata de la estructura entrar $N$ en alguien, donde el sustantivo de estado aparece como sujeto gramatical y el experimentador se realiza como locativo metafórico (el locus de la emoción o estado designado), generalmente introducido por la preposición en (cfr. nota 3). Este esquema sintáctico se ilustra con un ejemplo de principios del XX (14) y dos del Siglo de Oro ((15) y (16)). Adviértase que aquí el experimentador designa no solo personas u otros seres animados, sino también partes inalienables de un individuo (típicamente el corazón o el alma) ${ }^{12}$.

(14) Se dispersaron. Entró en ellos el pánico. (Sonata de estío, Ramón María del Valle Inclán, 1903)

(15) Era tanto el miedo que había entrado en su corazón, que no osaba apartarse un negro de uña de su amo. (Don Quijote I, Miguel de Cervantes, 1605)

(16) Por esta causa gran tristeza y lloro entró en los ánimos de los buenos vasallos del conde. (Historia general de España 8.7, Juan de Mariana, 1601)

Al igual que las otras dos estructuras con entrar, estas colocaciones son incoativas. La diferencia es que el esquema entrar $N$ en alguien está asociado con una CVA con haber. Por ejemplo, entra miedo en su corazón corresponde a hay miedo en su corazón, i.e. 'empieza a haber miedo en su corazón'. Como veremos más adelante, las colocaciones tipo entrar $N$ en alguien eran mucho más productivas en periodos anteriores que en el español actual.

Otro aspecto que contribuye al interés diacrónico de las colocaciones estudiadas es que dos de los esquemas sintácticos que acabamos de discutir presentan ciertas variaciones. En efecto, como documenta el $D C R(628$, s. v. entrar), entrar puede aparecer con nombres de estado pero sin un experimentador explícito, esto es, en el esquema entrar $N \emptyset$ (17). Además, también puede aparecer con un complemento dativo más un complemento locativo que designe una parte inalienable del experimentador. Se trata del esquema entrarle $N$ en (18), que también puede aparecer con morfología reflexiva, en la variante entrársele $N$ en (19).

\footnotetext{
12 Como en entrarle $N$ y entrar en $N$ (excepto entrar en calor), en estas estructuras también se puede modificar, relativizar y focalizar el nombre de estado, que conserva su autonomía sintáctica respecto a entrar.
} 
(17) Ahora, que cuando empieza a clarear entra un cansancio que ya no se puede..." (Es mi hombre 1, Carlos Arniches, 1921)

(18) [...] desde que [...] nos obligó a alterar [...] el rumbo que llevábamos, me entró en el alma la duda de la inoportunidad de nuestra empresa. (Motivos de Proteo, José Enrique Rodó, 1909)

(19) La negra duda se le entró en el pecho, y ahora vuelves a tu terrón sin la esperanza en ti mismo, sin el amor de ti mismo. (Motivos de Proteo, José Enrique Rodó, 1909)

Estas estructuras son variantes "híbridas" de los dos esquemas donde el sustantivo de estado sirve de sujeto gramatical de entrar, esto es, de entrarle $N$ y entrar $N$ en alguien. Por ejemplo, entra cansancio puede corresponder tanto a le entra cansancio como a entra cansancio en él/ella. Por otra parte, casos como (se) le entra miedo en el corazón están a caballo entre la estructura con experimentador dativo (le entra miedo) y la construcción con experimentador locativo (entra miedo en su corazón) porque el complemento dativo se interpreta como holónimo del complemento locativo (el merónimo) ${ }^{13}$.

En resumen, las colocaciones con entrar más sustantivo de estado resultan particularmente interesantes desde un punto de vista diacrónico porque ciertos nombres que hoy aparecen con experimentadores dativos (en la construcción entrarle $N$ ) también se documentan históricamente con experimentadores locativos (entrar $N$ en alguien) y con experimentadores sujeto (entrar en $N$ ), así como en ciertas variantes "híbridas" de los dos primeros esquemas (entrar $N \emptyset$, entrarle $N$ en y entrársele $N$ en). Aunque las fuentes lexicográficas indican que en el español moderno entrarle $N$ es la estructura más frecuente, no sabemos cuál era la distribución relativa de cada esquema en periodos anteriores, ni por qué hoy predomina la construcción con experimentador dativo. Estas son precisamente las dos preguntas básicas a las que intentamos responder con nuestro estudio de corpus.

\section{Metodología}

Nuestro estudio explora la distribución histórica de 56 sustantivos de estado en los distintos esquemas con entrar discutidos en la sección anterior. Los sustantivos estudiados comprenden una muestra representativa de los que se recogen (bajo entrar) en el REDES, el DEA, el DUE, el DRAE, el DCR y el Diccionario de colocaciones del Español o DiCE. Se seleccionaron atendiendo a dos

${ }^{13}$ Un merónimo designa una parte o un miembro de un todo (el holónimo). Como en otras lenguas románicas, en español un complemento dativo sirve a menudo de holónimo (Villar Díaz, 2004: 187-192). Por ejemplo, en le vendó la pierna a Eva, el dativo se interpreta como holónimo de pierna (el merónimo). 
criterios: (i) que puedan aparecer en el español moderno en el esquema entrarle $N$, y (ii) que se documenten en nuestro corpus desde el Medievo o (como muy tarde) a principios del Siglo de Oro. La lista incluye los sustantivos siguientes:

(20) aburrimiento, alegría, amor, angustia, ansia, aprensión, ataque, calambre, calentura (= 'fiebre; calor'), calor, cansancio, celos, codicia, cólera, curiosidad, desasosiego, deseo, dolor, duda, envidia, escalofrío, espanto, esperanza, fiebre, frío, furia, furor, gana(s), gozo, gusto, hambre, inquietud, ira, llanto, miedo, nervios, pánico, pasión, pavor, pena, placer, prisa, rabia, recelo, remordimiento, sed, sensación, sentimiento, sospecha, sudor, sueño, temblor, temor, tentación, terror, tristeza

Los datos se obtuvieron del Corpus del español, que abarca desde el siglo XIII al año 2000 e incluye más de cien millones de palabras de aproximadamente 20.000 textos peninsulares y latinoamericanos distribuidas aproximadamente a partes iguales en cinco periodos: del XIII al XV; el XVI; el XVII y el XVIII; el XIX; y el XX. El subcorpus del s. XX comprende, también a partes iguales, cuatro tipos de textos: académicos (especialmente de enciclopedias), ficción (novelas y relatos breves), noticias (sobre todo artículos de periódico), y textos orales (transcripciones de entrevistas y discursos). Se pueden buscar palabras exactas o frases, comodines, etiquetas, lemas, categorías gramaticales, colocaciones de hasta diez palabras, listas creadas por el usuario o cualquier combinación de estas opciones.

Puesto que la transmisión manuscrita de textos suele introducir cambios léxicos, ortográficos y morfosintácticos que pueden ser relevantes para el estudio diacrónico de las colocaciones (cfr. Fernández-Ordóñez, 2001: 391-398; 2002: 107-110, 114-153; y 2006: 1783-1784), nuestra clasificación cronológica de los textos medievales se basa no en la fecha de composición original, sino en la fecha de producción o copia del manuscrito. El Corpus del español indica los manuscritos exactos incluidos en el corpus, pero solo proporciona la fecha de composición original. La fecha de copia correspondiente se obtuvo de la Bibliography of Old Spanish Texts (Faulhaber et al, 1984) y PhiloBiblon (Faulhaber et al, 1997).

Treinta y ocho de los sustantivos estudiados se documentan en el Corpus del español desde el XIII (en cuanto a la fecha de copia); los otro dieciocho nombres se documentan por primera vez en el corpus (atendiendo siempre a la fecha de copia) en el XIV (ansia, curiosidad, furor, rabia y temblor), el XV (angustia, aprensión, ataque, calambre, cansancio, desasosiego, escalofrío, furia, inquietud, remordimiento, sensación y terror) o el XVI (pánico). La búsqueda en el corpus incluyó no solo la forma moderna de los sustantivos, sino también sus variantes históricas y ortográficas —que se identificaron utilizando el DCECH (Corominas y Pascual, 1980-1991) y el propio Corpus del espanol-, así como los correspondientes diminutivos, aumentativos y formas de 
plural. También se buscó todo el paradigma de dentrar, variante hipercorrecta de entrar (DCECH: 644, s. v. entrar).

\section{Resultados}

El corpus contiene un total de 463 ocurrencias relevantes de entrar con los sustantivos estudiados. Como sería de esperar, la mayoría de ocurrencias pertenecen a las tres estructuras básicas que vimos en la sección 1. De estas tres, la más frecuente es la construcción con experimentador sujeto (entrar en $N$ ), con 156 ocurrencias, de las cuales 26 pertenecen específicamente a entrar en calor. Las estructuras con experimentador dativo (entrarle $N$ ) les siguen de cerca, con 150 casos. En tercer lugar encontramos las colocaciones con experimentador locativo (entrar $N$ en alguien), con 102 ocurrencias. Estas tres estructuras básicas se ilustran a continuación con ejemplos del Medievo y el Siglo de Oro.

(21) entrarle $N$ (experimentador dativo) ${ }^{14}$

a. parad toda uia mientes en estado de uuestros enemigos [...] que quando uençieredes la delantera quebrantarsan sos coraçones \& entrarles a grand miedo \& uençer sean todos [...]. (Poridat de las poridades, Seudo-Aristóteles, compuesto y copiado s. XIII [Escorial, Monasterio L-III-2, ca. 1290-1300])

b. si mientes o iuras falso tos fiios comas assados \& cochos por fambre. \& tu fienta. con todo lo que combras te entre dolor de uientre que criebes. (Fuero General de Navarra, Versión B, trad. anónimo, compuesto s. XIII, copiado s. XIV [Dresden Sächsische Landesbibliothek - Staats- und Universitätsbibliothek Dresden App. 1761, 1300-1350])

c. Mas si le entrare poco a poco el sueño: e pereza: deue despertarse [...]. (Triunfo de amor, Juan Flores, compuesto y copiado s. XV [Madrid, Nacional ms. 22019, 1475-1505])

(22) entrar $N$ en alguien (experimentador locativo)

a. E tan grande fue el mjedo que enellos entro de aquel dia adelante que Sola mente non osauan sallir fuera de la çibdad. (Crónica de veinte reyes, anónimo, compuesto y copiado s. XIV [Escorial, Monasterio Y-I-12, 1390-1410])

b. Nunca en mí entrará el alegría que solía tener cuidando do está [...]. (Platir, anónimo, 1533)

${ }^{14}$ En este esquema sintáctico se documentan dos casos de laísmo, p. ej. (i), y uno de loísmo (ii).

(i) Luego la entró una curiosidad irresistible de saber quién fue y cómo era físicamente y si había tenido más hijos. (A fuego lento 2.14, Emilio Bobadilla, 1903)

(ii) [...] al fin había vencido el joven cristiano, y al punto lo había entrado un deseo tan encendido de recibir el bautismo, que [...]. (Predicación del Evangelio en las Indias 1.6, José de Acosta, 1577) 
c. Esto mismo es así en todos los que son discípulos de Cristo: miéntras está Cristo con ellos [...], no puede entrar en ellos tristeza ninguna; apartado Cristo de ellos [...], luego se entristecen, ántes no puede entrar alegria en ellos. (El evangelio según San Mateo, Juan de Valdés, 1540)

(23) entrar en $N$ (experimentador sujeto) ${ }^{15}$

a. Era descontra todos; el bon Rey tan temprado. Que non podie nenguno; seer su despagado. Tanto auie con todos; en grant amor entrado. Que se su padre fuesse [...]. (Libro de Alexandre, trad. anónimo, compuesto y copiado s. XIV [Madrid, Nacional Vitrina, 5-10, 1300-1400])

b. Este despues dela tirannia de lucio silla hauia entrado en muy grand cobdicia de tomar a su mano la cosa publica [...]. (Conjuración de Catilina, Salustio, trad. Francisco Vidal de Noya, compuesto y copiado s. XV [Zaragoza, Paulo Hurus, 1493])

c. [...] y es tanta la codicia en que han entrado por el interés, que no hay año ninguno que no salgan a esta guerra [...]. (Historia Argentina del descubrimiento, población y conquista de las provincias del Río de la Plata, Ruy Díaz de Guzmán, 1612)

El resto de ocurrencias pertenecen a las tres variantes sintácticas entrar $N \varnothing$ (37 casos), entrarle $N$ en (13 ocurrencias) y entrársele $N$ en (4 casos). Algunos ejemplos del Medievo y el Siglo de Oro se reproducen en (24)-(26). Además, también encontramos una ocurrencia de otra construcción que no se documenta en el DCR: la estructura entrarse $N$ en alguien. Esta variante reflexiva de la estructura básica con experimentador locativo corresponde al ejemplo (27).

(24) entrar $N \emptyset:[\ldots]$ por semejantes trabajos por los quales los espiritus se escalientan \& diminuyen el humor natural y entra la fiebre etica. (De proprietatibus rerum [Propiedades de las cosas], trad. Vicente de Burgos, compuesto y copiado s. XV [Toulouse, Enrique Meyer, 149409-18])

(25) entrarle $N$ en: Et tirara otrossi a omne sed. \& la calentura quel entra en el cuerpo. por razon del sol. (Lapidario, Alfonso X, compuesto y copiado s. XIII] [Escorial Monasterio h-I-15, ca. 1250])

(26) entrársele $N$ en: [...] de tal manera se le había entrado el temor en el alma. (Los trabajos de Persiles y Sigismunda, Miguel de Cervantes, 1617)

(27) entrarse $N$ en alguien: [...] pero que desde que oyó dicha proposición se habían entrado en su corazón vivos deseos de practicar lo propio, y que si [...]. (Relación histórica de la vida del Venerable Padre Fray Junípero Serra 2, Francisco Palou, 1787)

${ }^{15}$ Como en el español moderno, en el Medievo y el Siglo de Oro el sustantivo de estado goza de libertad sintáctica en estas colocaciones. La única excepción aparente es entrar en calor; desde las primeras atestaciones, calor no parece formar una unidad sintáctica independiente de la preposición en (cfr. sección 1 y nota 9). 
La Tabla 1 muestra la distribución histórica de cada tipo de estructura con entrar, utilizando ocurrencias por millón para facilitar la comparación entre siglos. Dado el bajísimo número de ocurrencias con morfología reflexiva, no se cuentan separadamente las variantes entrársele $N$ en y entrarse $N$ en alguien, sino que se incluyen en el conteo de las estructuras no reflexivas con las que se asocian (entrarle $N$ en y entrar $N$ en alguien, respectivamente). Para el esquema entrar en $N$, se proporcionan dos cifras: el número total de casos, y (entre paréntesis) el número de casos excluyendo las ocurrencias de entrar en calor. Esta distinción se realiza en vista del estatus especial de entrar en calor, donde, a diferencia de lo que observamos en otras estructuras, el sustantivo de estado carece de autonomía sintáctica (véanse las notas 9 y 15).

Como se muestra en la Tabla 1, las estructuras con experimentador dativo se documentan desde el XIII (atendiendo siempre a la fecha de copia, cfr. sección 2), aunque con una frecuencia muy baja. Las otras dos estructuras básicas (entrar $N$ en alguien y entrar en $N$ ) se documentan desde el XIV, un siglo antes que la variante entrar $N \varnothing$. Si nos concentramos en el total de casos (incluyendo todos los esquemas sintácticos), observamos un aumento generalizado en el uso de entrar en nuestras colocaciones entre el XIV y el XVIII, un ligero descenso en el XIX y otra bajada, un poco más marcada, en el XX.

Obviamente, los datos más interesantes de la Tabla 1 se refieren a la distribución relativa de cada estructura. Para simplificar la discusión, nos centramos exclusivamente en los tres esquemas básicos y dejamos de lado las estructuras híbridas entrar $N \varnothing$ y entrarle $N$ en, cuya inclusión no distorsionaría las tendencias generales que observamos. Al margen de un aumento puntual —aunque significativo- en el XVI, el esquema entrar $N$ en alguien se mantiene relativamente estable entre el XIV y el XVI, cuando se sitúa en primer lugar por encima de los otros dos patrones básicos. Sin embargo, las estructuras con experimentador locativo experimentan un descenso espectacular en el XVIII y vuelven a descender significativamente en el XX. Por otra parte, la construcción entrar en $N$ aumenta su frecuencia de uso entre el XIV y el XVIII, con una caída puntual en el XVI. El aumento es particularmente importante en el XVII (cuando pasa a ocupar el primer lugar, con más del $40 \%$ del total de casos) y el XVIII (cuando consolida su primer puesto, con más del $70 \%$ de casos). No obstante, el esquema con experimentador sujeto cae de forma significativa tanto en el XIX como en el XX (cuando solo representa ya entre un 17 y un $28 \%$ de casos, dependiendo de si incluimos entrar en calor en el conteo). Por último, el esquema entrarle $N$ se mantiene relativamente estable hasta el XVII y experimenta un aumento espectacular tanto en el XVIII (cuando pasa a ocupar el segundo lugar) como en el XIX (cuando se convierte en la estructura más frecuente). Aunque en el siglo XX sufre un ligero descenso, la construcción con experimentador dativo aún acapara la mayoría de casos (entre un 63 y un $73 \%$ del total, dependiendo siempre de si contamos entrar en calor). 


\begin{tabular}{|l|c|c|c|c|c|c|c|c|c|}
\cline { 2 - 10 } \multicolumn{1}{c|}{} & XIII & XIV & XV & XVI & XVII & XVIII & XIX & XX & Total \\
\hline entrarle $N$ & 0,14 & 0,37 & 0,46 & 0,28 & 0,22 & 1,16 & 3,27 & 2,73 & 1,48 \\
\hline entrarle $N$ en & 0,28 & & 0,46 & 0,17 & 0,30 & & 0,10 & 0,10 & 0,17 \\
\hline entrar $N \varnothing$ & & & 0,46 & 0,39 & 0,90 & 0,19 & 0,38 & 0,19 & 0,37 \\
\hline entrar $N$ en alguien & & 1,50 & 1,37 & 2,81 & 1,57 & 0,39 & 0,48 & 0,10 & 1,02 \\
\hline entrar en $N$ & & 0,37 & 1,26 & 0,73 & 2,55 & 4,36 & 1,30 & 1,22 & 1,54 \\
\hline sin entrar en calor & & $(0,37)$ & $(1,26)$ & $(0,51)$ & $(2,10)$ & $(4,16)$ & $(1,20)$ & $(0,63)$ & $(1,28)$ \\
\hline Total & 0,42 & 2,25 & 4,00 & 4,39 & 5,54 & 6,10 & 5,52 & 4,33 & 4,57 \\
\hline sin entrar en calor & $(0,42)$ & $(2,25)$ & $(4,00)$ & $(4,16)$ & $(5,09)$ & $(5,91)$ & $(5,43)$ & $(3,75)$ & $(4,31)$ \\
\hline
\end{tabular}

TABLA 1.-Ocurrencias por millón de entrar con los sustantivos estudiados.

El predominio del experimentador dativo en el siglo XX se aprecia con más detalle en la Tabla 2, que desglosa las ocurrencias por millón según el tipo de texto. Como podemos ver, en el XX entrar $N$ en alguien solo aparece (ocasionalmente) en obras de ficción. Aunque entrar en $N$ se documenta en los cuatro tipos de textos, la gran mayoría de casos son de entrar en calor ${ }^{16}$. Por otra parte, entrarle $N$ no aparece en noticias ni textos académicos, pero es más frecuente que todos los otros esquemas juntos tanto en ficción como en textos orales.

\begin{tabular}{|l|c|c|c|c|}
\cline { 2 - 5 } \multicolumn{1}{c|}{} & Ficción & Noticias & Noticias & Oral \\
\hline entrarle $N$ & 7,58 & & & 3,31 \\
\hline entrarle $N$ en & 0,39 & & & \\
\hline entrar $N \emptyset$ & 0,19 & & & 0,58 \\
\hline entrar $N$ en alguien & 0,19 & & & 0,19 \\
\hline entrar en $N$ & 3,30 & 0,98 & 0,19 & 0,39 \\
\hline sin entrar en calor & $(1,94)$ & $(0,59)$ & & \\
\hline Total & 11,66 & 0,98 & 0,19 & 4,48 \\
\hline sin entrar en calor & $(10,30)$ & $(0,59)$ & & $(4,09)$ \\
\hline
\end{tabular}

TABLA 2.-Ocurrencias por millón en el s. XX, según el tipo de texto.

Aunque entrar se documenta con los 56 sustantivos estudiados, no todos los nombres aparecen en los distintos esquemas sintácticos. La estructura más productiva es entrarle $N$, que aparece con 43 sustantivos (aburrimiento, amor, angustia, ansia, aprensión, ataque, calentura, calor, codicia, curiosidad, desasosiego, deseo, dolor, duda, envidia, escalofrio, esperanza, fiebre, frío, furia, furor, gana[s], gusto, hambre, inquietud, miedo, nervios, pánico, pavor, pena,

16 Típicamente, en los casos que no incluyen calor el sustantivo de estado aparece con un adjetivo estereotipado (p. ej. entrar en un sueño profundolen temores infundados), una indicación indirecta de la mayor fijación de este esquema sintáctico. 
placer, prisa, rabia, remordimiento, sensación, sentimiento, sudor, sueño, temblor, temor, tentación, terror, tristeza $)^{17}$. El segundo patrón más productivo es entrar $N$ en alguien, documentado con 27 sustantivos (alegría, amor, calor, celos, codicia, deseo, dolor, duda, envidia, espanto, esperanza, fiebre, frío, gusto, hambre, ira, miedo, pasión, pavor, pena, placer, rabia, recelo, sospecha, temor, tentación, tristeza $)^{18}$. Le sigue de cerca entrar en $N$, con 25 sustantivos (amor, aprensión, ataque, calor, celos, codicia, cólera, curiosidad, desasosiego, deseo, duda, esperanza, furia, furor, gana[s], gozo, ira, pánico, pena, placer, recelo, sospecha, sueño, temor y tentación). Respecto a las variantes "híbridas", entrar $N \emptyset$ aparece con 18 nombres (amor, calentura, cansancio, celos, codicia, deseo, dolor, duda, fiebre, frío, gana[s], gozo, gusto, llanto, miedo, prisa, sospecha y sueño), y entrar(se)le $N$ en, con nueve (amor, calambre, calentura, codicia, duda, frío, rabia, sed y temor).

En (28) se muestra qué sustantivos se documentan en cada uno de los tres esquemas básicos en cada siglo. Como podemos ver, si dejamos de lado el siglo XIII (donde el único esquema básico representado es entrarle $N$ ), la distribución que se muestra en (28) corrobora la existencia de los tres periodos diferenciados que observábamos en la Tabla 1: del XIV al XVI (con una mayoría de entrar $N$ en alguien y un uso relativamente bajo de los otros dos esquemas básicos); el XVII y el XVIII (marcados por un predominio claro de entrar en $N$, acompañado por un descenso muy marcado de entrar $N$ en alguien y una generalización de entrarle $N$ ); y a partir del XIX (cuando entrarle $N$ pasa a dominar ampliamente).

(28) Sustantivos documentados en cada estructura básica, por siglo:

a. S. XIII: entrarle $N$ : miedo; entrar $N$ en alguien: $\varnothing$; entrar en $N$ : $\varnothing$

b. S. XIV: entrarle $N$ : dolor; entrar $N$ en alguien: amor, codicia, envidia, miedo; entrar en $N$ : amor

c. S. XV: entrarle $N$ : esperanza, frío, miedo, sueño; entrar $N$ en alguien: alegría, amor, dolor, envidia, espanto, frío, hambre, miedo; entrar en $N$ : amor, codicia, ira, pena, sueño, temor, tentación

d. S. XVI: entrarle $N$ : calor, deseo, miedo, placer, temor; entrar $N$ en alguien: alegría, amor, calor, celos, dolor, envidia, espanto, esperanza, ira, pasión, pavor, placer, rabia, recelo, temor, tristeza; entrar en $N$ : amor, calor, codicia, cólera, duda, gozo, temor, tentación

${ }^{17} \mathrm{El}$ total de sustantivos que aparecen potencialmente con un experimentador dativo aumenta a 50 si añadimos siete nombres más (calambre, cansancio, celos, gozo, llanto, sed y sospecha) documentados en las variantes "híbridas" entrarle $N$ en y entrar $N \emptyset$. La falta de ejemplos de entrarle $N$ con alegría, cólera, ira y recelo resulta un tanto sorprendente, y nos recuerda que, a pesar de sus ventajas, incluso los corpus históricos más completos no siempre reflejan todas las posibilidades que encontramos en la lengua "real".

${ }^{18} \mathrm{El}$ total de sustantivos que aparecen potencialmente con un experimentador locativo aumenta a 36 si añadimos nueve sustantivos más (calambre, calentura, cansancio, gana(s), gozo, llanto, prisa, sed y sueño) documentados en las variantes "híbridas" entrarle $N$ en y entrar $N \emptyset$. 
e. S. XVII: entrarle $N$ : deseo, frío, furia; entrar $N$ en alguien: alegría, amor, celos, miedo, pasión, pena, rabia, sospecha, tentación; entrar en $N$ : aprensión, calor, celos, codicia, deseo, duda, esperanza, furor, gana(s), gozo, pena, placer, recelo, sospecha, temor

f. S. XVIII: entrarle $N$ : calentura, deseo, duda, esperanza, fiebre, frío, miedo, rabia, sudor, temor, tristeza; entrar $N$ en alguien: amor, deseo, gusto, miedo; entrar en $\mathrm{N}$ : aprensión, calor, cólera, deseo, duda, esperanza, furia, furor, recelo, sospecha, sueño, temor

g. S. XIX: entrarle N: aprensión, codicia, curiosidad, desasosiego, deseo, dolor, envidia, escalofrío, esperanza, fiebre, frío, furia, furor, gana(s), hambre, miedo, pánico, rabia, remordimiento, sudor, sueño, temblor, temor, tentación, terror, tristeza; entrar $N$ en alguien: celos, duda, envidia, espanto, miedo, recelo, sospecha, temor; entrar en $N$ : amor, aprensión, calor, cólera, curiosidad, deseo, duda, recelo, sospecha, temor, tentación

h. S. XX: entrarle $N$ : aburrimiento, amor, angustia, ansia, ataque, calambre, calentura, curiosidad, deseo, dolor, duda, escalofrío, frío, furia, gana(s), gusto, inquietud, miedo, nervios, pánico, pavor, pena, prisa, rabia, remordimiento, sensación, sentimiento, sueño, temor, terror; entrar $\mathbf{N}$ en alguien: fiebre, frío; entrar en $\mathbf{N}$ : ataque, calor, desasosiego, furor, ira, pánico, sospecha, sueño

Para muchos de los sustantivos estudiados, el número de ocurrencias es demasiado bajo como para comparar cambios individuales en la distribución relativa de cada patrón sintáctico. Además, un número sustancioso de nombres se documenta solo en una de las tres construcciones básicas ${ }^{19}$. Sin embargo, un análisis de aquellos sustantivos con los que entrarle $N$ compite a dos o tres bandas con entrar $N$ en alguien o entrar en $N$ es consistente con nuestros resultados generales ${ }^{20}$. En efecto, con tales nombres los experimentadores dativos suelen ser menos frecuentes hasta el siglo XIX, cuando empiezan a predominar. La única excepción notable es calor, con el que el esquema entrar en $N$ predomina en todos los siglos. Estos datos sugieren que el triunfo generalizado de los experimentadores dativos a partir del XIX se debió no solo a que entrarle $N$ se extendió a más sustantivos, sino también a que este esquema aumentó su frecuencia de uso con los sustantivos con los que ya se documentaba en siglos anteriores.

19 De estos, catorce aparecen con entrarle $N$ (aburrimiento, angustia, ansia, calentura, escalofrío, inquietud, nervios, prisa, remordimiento, sensación, sentimiento, sudor, temblor y terror), dos con entrar en $N$ (cólera y gozo), y tres con entrar $N$ en alguien (alegría, espanto y pasión).

${ }^{20}$ Entrarle $N$ compite a tres bandas con los otros dos esquemas con diez sustantivos (amor, calor, codicia, deseo, duda, esperanza, pena, placer, temor y tentación). Compite a dos bandas con entrar $N$ en alguien con otros diez nombres (dolor, envidia, fiebre, frío, gusto, hambre, miedo, pavor, rabia y tristeza), y con entrar en $N$ con nueve más (aprensión, ataque, curiosidad, desasosiego, furia, furor, ganas, pánico y sueño). 
El análisis se completó con un estudio de aquellos casos en los que un mismo sustantivo aparece en el mismo texto en dos construcciones diferentes con entrar. Además del ejemplo con entrarle/entrársele duda en, que, como vimos en (18) y (19), coexisten en Motivos de Proteo, de principios del XX; encontramos tales dobletes con otros cuatro nombres: frío, documentado tanto con entrarle $N$ como con entrar $N$ en alguien en un texto del XV (29); placer, que aparece en esos dos mismos esquemas en un libro de caballerías del XVI (30); temor, documentado también con entrarle $N$ y entrar en $N$ alguien en una obra del XVIII (31); y calor, usado tanto en la estructura entrar $N$ en alguien como en la construcción entrar en $N$ en un texto del XVI (32).

(29) Libro de albeitería (trad. Martín Martínez de Ampiés, compuesto y copiado s. XV [Zaragoza, Paulo Hurus, 1499-10-16])

a. [...] y con vna manta le abriguen todas las espaldas / y ahun la naffra con todos los pechos: porque ningun viento ni frio le entre que le seria mucho dañoso [...].

b. [...] y no le de viento enel establo donde estouiere mas bien amantado le tengan que frio no pueda entrar en todo su cuerpo: ya mucho menos dentro enla naffra.

(30) Espejo de príncipes y caballeros (Diego Ortúñez de Calahorra, 1555)

a. [...] el Cavallero del Febo mostrava tanta pena y lançava unos sospiros tan profundos que bien sentía la princessa el gran dolor que en el coraçón tenía [...]. Mas queriendo que aquel plazer le entrasse poco a poco, baxando la visera del yelmo [...]. (Libro III)

b. Y assí, se partieron de allí y se bolvieron por donde havían venido, tan tristes y desconsolados que no se podían consolar, ni por largos días pudo entrar plazer ni alegría en ellos. (Libro II)

(31) Historia del Reino de Quito en la América Meridional, tomo II y parte II, que contiene la historia antigua (Juan de Velasco, 1789)

a. Belalcázar perdió casi todos sus Indianos Cañares [...]; y se retiró con tanto número de heridos que comenzaron a entrarle muchas dudas y temores.

b. Mas habiendo entrado el Virrey en grandísimos temores con la falsa voz de que eran 500 [...].

(32) Libro de la oración y meditación (Fray Luis de Granada, 1554)

a. [...] tengamos un poco de paciencia y longanimidad, porque poco a poco irá entrando en nuestra ánima el calor de la devoción, y así como él fuere entrando, así se irá resolviendo [...].

b. Porque, ¿de dónde nace, si piensas, que unos, en allegándose a la oración, luego entran en calor, y otros, a cabo de mucho tiempo y trabajo, apenas pueden quietar el corazón?

En tres de los textos donde se documentan estos dobletes (Libro de albeitería, Libro de la oración y meditación, y Motivos de Proteo) solo encontramos una ocurrencia de cada esquema. Sin embargo, el Espejo de príncipes y caballeros contiene cinco casos de entrar plazer en alguien y uno de entrarle plaz- 
er, mientras que la Historia del Reino de Quito incluye cuatro ocurrencias de entrar en temor y una de entrarle temor. Estos patrones distribucionales no solo demuestran que algunos hablantes utilizaban entrarle $N$ junto con los otros esquemas básicos ya desde finales del Medievo (al menos con ciertos sustantivos); también son consistentes con el predominio inicial de entrar $N$ en alguien, el ascenso posterior de entrar en $N$, y la victoria generalizada del esquema dativo a partir del $\mathrm{XIX}^{21}$.

\section{DisCUSIÓN}

\subsection{Orígenes de las colocaciones con entrar más sustantivos de estado}

Las tres estructuras básicas con entrar que estudiamos aquí tienen su origen en el latín clásico (siglos I a.C. a III d. C.). En este periodo INTRARE (el predecesor de entrar) aparecía en tres tipos de esquemas sintácticos fuera de nuestras colocaciones: con complementos acusativos, p. ej. DOMUM INTRARE 'entrar en/a una casa'; con sintagmas preposicionales tipo IN + acusativo, p. ej. IN HORTOS INTRARE 'entrar en jardines'; $y$, en usos poéticos, con dativos, p. ej. MONTIBUS INTRARE 'entrar en/a las montañas' (Lewis y Short, 1879). Varios diccionarios (Lewis y Short, 1879; Latham y Howlett, 1975), así como las bases de datos Perseus (Crane, 1992) e Itinera Electronica (Meurant, 1998), documentan estos tres esquemas con INTRARE con sustantivos de estado en textos clásicos. Concretamente, la estructura con acusativo se documenta con CALOR 'calor', CUPIDO 'deseo', DOLOR 'dolor', GLORIA 'gloria, vanagloria', METUS 'miedo', PAVOR 'pavor' y PUDOR 'vergüenza', mientras que la construcción con dativo aparece con DISCORDIA 'discordia', y la estructura IN + acusativo con TIMOR 'temor' y SOMNUS 'sueño'. Como se ilustra a continuación, en estas construcciones el nombre de estado sirve de sujeto gramatical de INTRARE. El otro complemento suele designar un experimentador animado (un individuo o una parte inalienable de su cuerpo, como en (33)-(35)), pero también puede ser un lugar $(36)^{22}$.

\footnotetext{
${ }^{21}$ Los datos sugieren que la sustitución de entrar en $N$ por entrarle $N$ a partir del XIX afectó tanto al español peninsular como al de América, si bien es cierto que (con aquellos nombres que muestran una alternancia histórica entre estos dos esquemas, excluyendo calor) en los siglos XIX y XX entrar en $N$ se suele documentar con más frecuencia en América que en España (por ejemplo, las tres únicas ocurrencias de entrar en pánico del XX pertenecen a variedades americanas). Por otra parte, no hay tendencias claras que sugieran un posible efecto del tipo de texto en el proceso de sustitución de un esquema por otro (cfr. Kabatek, 2005). Estas diferencias dialectales y de tipología textual deberían examinarse con más detalle en investigaciones futuras.

${ }^{22}$ Salvo (33), que proviene de Perseus, los otros ejemplos se obtuvieron de Itinera. La traducción es mía.
} 
(33) TUA, DIVE AUGUSTE, CAELO RECEPTA MENS, TUA, PATER DRUSE, IMAGO, TUI MEMORIA ISDEM ISTIS CUM MILITIBUS, QUOS IAM PUDOR ET GLORIA INTRAT, ELUANT HANC MACULAM [...]. 'Que tu mente, recibida en el cielo, ¡oh, divino Augusto!, tu imagen, ¡oh, padre Druso!, y tu recuerdo, con estos mismos soldados, a los que ahora les entra vergüenza y vanagloria, limpien esta mancha [...].' (Anales 1.43, Cornelio Tácito, ca. $115-117$ d.C.)

(34) ILLE REPENTE / ACCEPIT SOLITAM FLAMMAM, NOTUSQUE MEDULLAS / INTRAUIT CALOR ET LABEFACTA PER OSSA CUCURRIT. 'De repente sintió aquella llama familiar, y un calor acostumbrado le entró en la entrañas y recorrió sus debilitados huesos.' (Eneida 8.388-390, Virgilio, s. I a.C.)

(35) SI ULTIMUM DIEM NON QUASI POENAM SED QUASI NATURAE LEGEM ASPICIS, EX QUO PECTORE METUM MORTIS EJECERIS, IN ID NULLIUS REI TIMOR AUDEBIT INTRARE. 'Si consideras tu último día no como un castigo, sino como una ley de la naturaleza, ningún temor osará entrar en un corazón del que habrás expulsado el miedo a la muerte.' (Diálogos 12.13.2, Lucio Anneo Séneca, 3762 d.C.)

(36) DISCORDIA DEMENS / INTRAUIT CAELO SUPEROSQUE AD BELLA COEGIT. 'Una discordia desenfrenada entró al cielo y empujó a los dioses a la guerra.' (Las guerras púnicas 9.288-289, Silio Itálico, s. I d.C.)

INTRARE también se combinaba con sustantivos predicativos que aparecían (en caso acusativo) como objeto de la preposición IN. Aunque en las fuentes consultadas (Perseus, Itinera Electronica; Glare, 1996; Latham y Howlett, 1975; Lewis y Short, 1879; White y Riddle, 1872) no se incluyen ejemplos con nombres de estado, sí hay casos con otros sustantivos predicativos:

(37) ISTE IN POSSESSIONEM BONORUM MULIERIS ENTRAT, IPSAM VENERI IN SERUITUTEM ADIUDICAT. 'Este entra en posesión de los bienes de la mujer, y a ella misma la adjudica a Venus en esclavitud.' (Discurso contra Cecilio 17.56, Marco Tulio Cicerón, s. I a.C.)

Las colocaciones del español descienden directamente de estas construcciones, pero con algunos cambios. Así, la construcción con experimentador locativo (entrar $N$ en alguien) refleja la pérdida de la marca de caso acusativo en español, un cambio totalmente regular que llevó a reinterpretar lo que en latín era un complemento direccional (IN + acusativo) como un locativo metafórico. La construcción con experimentador sujeto (entrar en $N$ ) también refleja esta pérdida del caso acusativo, pero además parece haber implicado una extensión de dicha estructura a los sustantivos de estado (con los que - a juzgar por la falta de ejemplos relevantes - no parecía muy productiva en el latín clásico). Finalmente, la estructura con dativo (entrarle $N$ ) refleja no solo el desarrollo de los pronombres clíticos romances, sino también la generalización de la estructu- 
ra original más allá del lenguaje poético con el que estaba asociada en el latín $(\text { cfr. nota } 3)^{23}$.

\subsection{El ocaso de los experimentadores locativos}

El ascenso del esquema entrarle $N$ con sustantivos de estado en el español moderno conllevó dos cambios consecutivos: el triunfo de dicho esquema sobre los experimentadores locativos en el XVIII, y, un siglo más tarde, su victoria sobre entrar en $N$. En lo que sigue discutimos el primer cambio, y en la sección 4.3 abordamos el segundo.

Como hemos visto, hoy en día las colocaciones tipo entrar $N$ en alguien (o en una parte de su cuerpo) son poco frecuentes y suelen asociarse con un complemento locativo que designa un colectivo humano. Por ejemplo, en (38) España puede interpretarse no solo como un lugar geográfico (esto es, como un locativo auténtico, cfr. había fiebre en España), sino también como un colectivo humano (y, por tanto, como el experimentador animado que caracteriza las colocaciones entrarle $N$, cfr. a España le entró fiebre).

(38) [...] por esa, esa fiebre que ha entrado en España, ¿no?, de que todo el mundo debe tener un título universitario [...]. (Habla Culta de Madrid (España): M4)

Ejemplos como (38) resultan particularmente interesantes porque, históricamente, entrar también se documenta con sustantivos de estado en estructuras con locativos inanimados que no pueden interpretarse como experimentadores, esto es, en el esquema entrar $N$ en un lugar, p.ej.

(39) [...] por razon dela espesura dela corteza de aquel fruto: que el frio non puede entrar enla piña y tiene su calentura natural allegada a dentro. (Sevillana Medicina, Moisés ben Samuel de Roquemaure, compuesto s. XIV, copiado s. XVI [Sevilla, Andrés de Burgos, 1545-05-11])

\footnotetext{
${ }^{23}$ La distribución de los esquemas entrarle $N$ y entrar en $N$ en las lenguas romances modernas sugiere que la generalización de dichos esquemas habría tenido lugar ya en el latín tardío o el romance temprano, pero con una diferencia importante: mientras que el uso de entrar en $N$ con sustantivos de estado se habría extendido por toda la Romania, la generalización de las estructuras tipo entrarle $N$ habría sido más limitada. Esta hipótesis explicaría por qué mientras que el catalán, el italiano, el francés y el portugués, al igual que el español, aceptan el esquema entrar en $N$ con nombres de estado (p. ej. catalán entrar en sospites 'entrar en sospechas', francés entrer en colère 'entrar en cólera'), la estructura tipo entrarle $N$ solo es productiva, aunque en diferentes grados, en las dos primeras lenguas, p. ej. catalán m'entra un dubte / italiano mi entra un dubbio 'me entra una duda' (Académie française, 1986; Houaiss, 2001; Institut d'Estudis Catalans, 19852007; Zingarelli et al., 2010).
} 
Como se muestra en la Tabla 3, las estructuras entrar $N$ en un lugar también experimentaron una caída estrepitosa en el XVIII. Este paralelismo cronológico confirma que el XVIII fue un punto de inflexión clave en las colocaciones con entrar y sugiere que la caída en desuso de los experimentadores humanos (entrar $N$ en alguien) se enmarca dentro de un declive más general de las construcciones locativas con entrar más sustantivos de estado.

\begin{tabular}{|l|c|c|c|c|c|c|c|c|c|}
\cline { 2 - 9 } \multicolumn{1}{c|}{} & XIII & XIV & XV & XVI & XVII & XVIII & XIX & XX & Total \\
\hline entrar $N$ en un lugar & 0,57 & 0,75 & 1,49 & 1,46 & 1,57 & 0,29 & 0,43 & 0,19 & 0,81 \\
\hline
\end{tabular}

TABLA 3.-Ocurrencias por millón de entrar $N$ en un lugar con nuestros 56 nombres de estado.

Al margen de este declive general, el factor más importante en la caída en desuso de entrar $N$ en alguien es un cambio gramatical con un alcance mucho mayor: el triunfo del dativo como realización canónica del experimentador en las construcciones del español que indican procesos físicos o mentales de tipo involuntario. Para entender este cambio, es necesario expandir nuestra discusión a la victoria de entrarle $N$ sobre el esquema con experimentador sujeto.

\subsection{El declive de los experimentadores sujeto}

Como ya sabemos, las estructuras con experimentador sujeto (entrar en $N$ ) predominaron en el XVII y el XVIII tras un aumento vertiginoso en ambos siglos, pero cayeron en picado en el XIX y el XX y fueron desplazadas por el esquema entrarle $N$. El descalabro de entrar en $N$ a partir del XIX no puede atribuirse a un declive general de este esquema, que todavía es productivo con otros nombres que no aparecen en las colocaciones tipo entrarle $N$, p. ej. acción, coma, guerra y peligro — véanse ejemplos (6) y (7) (cfr. Bosque, 2004: 944)—. De hecho, como se ilustra en la Tabla 4, la frecuencia de uso de entrar en $N$ con estos otros nombres aumentó en el Xx. Este detalle confirma que la caída en desuso de entrar en $N$ solo afectó sistemáticamente a los sustantivos de estado que ahora aparecen con experimentador dativo.

\begin{tabular}{|l|c|c|c|c|c|c|c|c|c|}
\cline { 2 - 9 } \multicolumn{1}{c|}{} & XIII & XIV & XV & XVI & XVII & XVIII & XIX & XX & Total \\
\hline entrar guerra & 0,14 & & 0,46 & 0,62 & 0,15 & 0,58 & 0,29 & 2,24 & 0,75 \\
\hline
\end{tabular}

TABLA 4.-Ocurrencias por millón de entrar en guerra.

Tres son los factores principales que explicarían la victoria generalizada de entrarle $N$ sobre entrar en $N$ con los sustantivos de estado. El primero es la caída en desuso de muchas combinaciones del tipo en + sustantivo de estado, 
que constituyen la base de la colocación más amplia entrar en $N$ (recuérdese que, como vimos en la sección 1, las colocaciones tipo entrar en $N$ incluyen otra colocación formada por el sintagma preposicional encabezado por en). En el Medievo y el Siglo de Oro las colocaciones en + sustantivo de estado eran mucho más productivas y se documentaban frecuentemente no solo en Construcciones con Verbo de Apoyo con estar (o ser, en los textos más antiguos), sino también con verbos como caer, meter, poner, tener y venir, entre otros (cfr. Dubský, 1962: 35-38). Los ejemplos siguientes ilustran estas posibilidades con una colocación ya desaparecida: en temor.

(40) [...] \& porque estauan en grande temor pensauan lo peor cada dia [...]. (Gran conquista de ultramar, anónimo, compuesto s. XIII, copiado s. XVI [Salamanca, Giesser, 1503-06-21])

(41) Cayó en temor de los que más suelen penar a la hora postrera. (Avisos y reglas cristianas para los que desean servir a Dios, San Juan de Ávila, 1556)

(42) Entonces fue metido en temor de muerte, porque puesto que quisiesse dexar el espada no se podía apartar [...]. (Felixmarte de Hircania 1.47, Melchor de Ortega, 1556)

(43) [...] essa vuestra ferida tal: \& en tal lugar: os daria dolor \& pornia en temor. (Letras, Fernando del Pulgar, compuesto s. XV, copiado s. XVI [Sevilla, Estanislao Polono, 1500-04-24])

(44) Mi seso malamente descomponen; en maravilla y en temor me tienen, y en ansia me sostienen, tanto, que [...]. (Canción 21, Juan Boscán, s. $\mathrm{XVI})$

(45) [...] temieron la voz de Dios: Y en pecando un hombre, luego viene en temor, que quiera ó no. (Epistolario espiritual, San Juan de Ávila, 1578)

Hoy en día todavía encontramos colocaciones con en y ciertos sustantivos de estado, p. ej. duda, crisis y estado (de...). Como se ilustra en (46), tales combinaciones siguen apareciendo en la CVA con estar que sirve de punto de partida para entrar en $N$ (cfr. nota 9).

(46) Y yo como estaba en duda entre..., matemáticas e historia dije... bueno, voy [...]. (Habla Culta de Lima (Perú): M15)

Sin embargo, la gran mayoría de colocaciones tipo en + sustantivo de estado han caído en desuso o incluso desaparecido por completo (cfr. en alegríal amor/ miedo/temor). Esta situación contrasta con lo que observamos con otros sustantivos predicativos que todavía resultan muy productivos en la estructura entrar en $N$ (pero que no son incompatibles con el esquema entrarle $N$ ), p. ej. coma, guerra y peligro (véase nota 10). Al igual que duda, estos otros sustantivos todavía aparecen con entrar precisamente porque siguen siendo productivos con la preposición en y, por consiguiente, también en una CVA con estar. 
La hipótesis que se baraja aquí es que la mayoría de colocaciones del tipo entrar en temor, a diferencia de las estructuras tipo entrar en guerra, han desaparecido porque se ha perdido la colocación con en y el sustantivo correspondiente (y, por ende, también la CVA con estar; cfr. estar con temor). En contraste, el esquema entrarle $N$ todavía resulta productivo con los sustantivos de estado porque dichos nombres siguen usándose en la CVA con tener que se asocia con la construcción dativa (p. ej. Miguel tiene temor, cfr. sección 1).

La segunda razón por la que entrarle $N$ se habría impuesto a entrar en $N$ con los sustantivos de estado tiene que ver con una propiedad estructural que el primer esquema, a diferencia del segundo, comparte con entrar $N$ en alguien y las variantes híbridas entrar $N \emptyset$ y entrarle $N$ en: la realización del nombre predicativo como sujeto gramatical. Históricamente, esta realización parecía mucho más arraigada que el esquema donde el experimentador aparece como sujeto (entrar en $N$ ), pues no solo se documenta con más sustantivos diferentes en cada uno de los ocho siglos estudiados — véase (28)—, sino que también suma una amplia mayoría de ocurrencias (típicamente por encima del 70\%) en todos los siglos excepto el XVIII (Tabla 1). Esta preferencia histórica por el sustantivo de estado como sujeto - que, a juzgar por las observaciones que hicimos en la sección 4.1, parece remontarse al latín clásico-, habría impedido que entrar en $N$ se estableciera definitivamente cuando la estructura con experimentadores locativos cayó en desuso, favoreciendo el triunfo posterior de entrarle $N$.

El tercer factor en el declive de entrar en $N$ en nuestras colocaciones es el mismo que habría contribuido al ocaso de los experimentadores locativos: el triunfo generalizado de los experimentadores dativos en las estructuras del español que expresan emociones o sensaciones involuntarias. Entre los verbos afectados por este cambio, el más importante —y el más estudiado hasta la fechaes gustar, cuya historia es de gran relevancia para entender lo que ocurrió en nuestras colocaciones. Inicialmente, gustar tenía un experimentador sujeto que aparecía en estructuras transitivas (yo gusto algo) o preposicionales (yo gusto de algo), con una preferencia por estas últimas a partir del XVII (Melis 1998: 298, Vázquez Rozas y Rivas 2007: 150-152). La estructura con experimentador dativo (me gusta algo) se documenta desde finales del XVI, pero solo empieza a predominar a partir de la segunda mitad del XVIII (Vázquez Rozas y Rivas, 2007: 152; cfr. Elvira, 2011: 197 y Melis, 1998: 299). El ascenso meteórico del experimentador dativo puede observarse claramente en la Tabla 5, donde se analiza una muestra de 100 ocurrencias de gustar por siglo seleccionadas al azar entre el XVII y el XX mediante una función del Corpus del español que permite este tipo de muestreo aleatorio. Como podemos ver, el experimentador sujeto domina claramente con gustar en el XVII y el XVIII, pero a partir del XIX 
(el mismo siglo en el que entrarle $N$ triunfa sobre entrar en $N$ ) el esquema dativo se impone rotundamente ${ }^{24}$.

\begin{tabular}{|l|c|c|c|c|}
\cline { 2 - 5 } \multicolumn{1}{c|}{} & XVII & XVIII & XIX & XX \\
\hline sujeto (yo gusto...) & 95 & 65 & 37 & 3 \\
\hline dativo $($ me gusta...) & 5 & 35 & 63 & 97 \\
\hline
\end{tabular}

TABLA 5.-Porcentaje de ocurrencias de gustar con experimentador sujeto y experimentador dativo en los siglos XVII a XX, basado en un muestreo aleatorio de 100 ocurrencias por siglo.

El hecho de que la sustitución generalizada del experimentador sujeto por el experimentador dativo coincida cronológicamente tanto con gustar como en las colocaciones con entrar sugiere que nos encontramos ante un cambio gramatical sistemático y de gran envergadura. Dicho cambio podría conceptualizarse utilizando el análisis construccionista que Vázquez Rozas y Rivas (2007) proponen en su estudio sobre gustar. Siguiendo el marco teórico desarrollado por Goldberg $(1995,2003)$ y otros, estas investigadoras entienden el término 'construcción' en el sentido técnico de una unidad básica de representación sintáctica que tiene carácter simbólico, al asociar una forma con un significado. Dicho de otro modo, una construcción tiene correlatos semánticos y sintácticos que se añaden a la semántica del verbo y determinan la estructura de la cláusula. Vázquez Rozas y Rivas caracterizan la estructura gustarle como una de las múltiples realizaciones léxicas de una construcción muy productiva del español: la construcción con dativo. Esta construcción (en adelante S-V-I) asocia la estructura intransitiva SUJETO-VERBO-COMPLEMENTO INDIRECTO con el significado prototípico de "la relación entre dos participantes, uno de los cuales, el estímulo, desencadena involuntariamente una sensación o emoción en el otro participante, el experimentador" (160). La construcción S-V-I se remonta ya al latín, donde aparecía preferentemente con PLACERE (el étimo de placer) y verbos similares (Vázquez Rozas y Rivas, 2007: 158; cfr. Bauer, 1998: 103; Elvira, 2011: 192-193 ${ }^{25}$. En el español ha sido productiva desde los orígenes del idioma hasta la actualidad; con el paso del tiempo ha ido incorporando nuevos verbos y ha adquirido un grado de consolidación cognitiva que le ha permi-

\footnotetext{
${ }^{24}$ La Tabla 5 corrobora la observación de Vázquez Rozas y Rivas (2007: 153), basada en la información obtenida de la Base de Datos Sintácticos del español actual, de que el esquema dativo representa el $97,44 \%$ de usos de gustar hoy en día (cuando el experimentador sujeto solo aparece en fórmulas como cuando Ud. guste).

${ }^{25}$ Parece que esta construcción se remonta incluso a etapas anteriores del desarrollo de la familia de lenguas indoeuropeas: como documentan Barðdal et al. (2012), los predicados que aparecían con experimentador dativo en varias lenguas indoeuropeas antiguas además del latín pertenecían a ciertas clases semánticas relativamente homogéneas que denotan "una falta de control por parte del referente sujeto" (535).
} 
tido seguir generalizándose a pesar de la presión de otra estructura menos marcada tipológicamente: el esquema transitivo del tipo yo gusto algo (Elvira, 2011: 184-202; Vázquez Rozas y Rivas, 2007: 158-162)26. La productividad histórica de la construcción S-V-I se demuestra por el hecho de que (i) estaba muy arraigada con los dos verbos de emoción más frecuentes en el Medievo, esto es, pesar y placer, a los que gustar sustituyó heredando su esquema sintáctico; (ii) se ha extendido a partir del XVII a verbos que en periodos anteriores solo tenían usos transitivos, incluyendo agradar, apetecer y verbos causativos emocionales tales como sorprender, molestar, divertir y emocionar, entre otros; y (iii) las nuevas creaciones léxicas del español actual correspondientes al ámbito semántico de gustar reproducen su mismo esquema sintáctico, p. ej. le chifla/mola (Elvira, 2011: 198-199 y 201; Melis, 1998: 302-303; Vázquez Rozas y Rivas, 2007: 153-154) ${ }^{27}$.

Volviendo a las colocaciones con entrar (donde, recordémoslo, el experimentador dativo se documenta ya desde el XIII), el triunfo de la construcción SV-I parece haber ocurrido por etapas: al parecer, los experimentadores dativos se impusieron inicialmente sobre los locativos en el XVIII, y, un siglo después,

\footnotetext{
${ }^{26}$ Según el enfoque construccionista, la selección de una cierta construcción implica una particular conceptualización de la experiencia, que a su vez depende de la forma en que los seres humanos percibimos y experimentamos la realidad. La prominencia sicológica y la frecuencia de uso condicionan el grado de consolidación de una construcción (Vázquez Rozas y Rivas, 2007: 157-158). Estos factores sicológicos y culturales explicarían por qué la evolución de verbos como gustar en español sigue la dirección opuesta de la de sus equivalentes en inglés, donde una alternancia similar se resolvió con el triunfo del experimentador sujeto (p. ej. I like) sobre el experimentador dativo (cfr. inglés antiguo me liketh; cfr. Talmy, 2000: 98-101).

${ }^{27}$ Al igual que Vázquez Rozas y Rivas, Elvira (2011) también propone un análisis construccionista de las estructuras con dativo del español. Sin embargo, Elvira caracteriza el significado prototípico de la construcción que nosotros denominamos S-V-I en términos más generales, esto es, como un estado o evento no controlado. Su caracterización semántica engloba no solo los verbos sicológicos, sino también verbos modales como convenir, verbos de exceso como bastar, faltar y sobrar, y colocaciones (o "frases verbales", en su propia terminología) como dar asco y venir bien (189-190, 202). Aunque aquí adoptamos la caracterización de Vázquez Rozas y Rivas, la propuesta de Elvira también es compatible con nuestro análisis.

Otro análisis construccionista que tampoco adoptamos aquí es el que propone Rivero (2010) dentro de un enfoque minimista. Rivero se centra específicamente en dos tipos de estructuras: con verbos estativos como plazer, gustar y apetecer (donde el experimentador se realizaba originalmente como un sintagma dativo sin redoblamiento clítico); y con verbos télicos como antojársele y olvidársele (que aparecían desde el principio con un clítico dativo). Para explicar este contraste, Rivero propone que en el Medievo había dos tipos de construcciones con experimentadores dativos: una construcción aplicativa para los verbos télicos; y una construcción locativa para los verbos estativos. La construcción aplicativa que definía originalmente el esquema télico se extendió más tarde a los verbos atélicos, de manera que la opción locativa desapareció (187-190). El análisis de Rivero resulta de gran interés, pero no queda del todo claro que los casos donde se asume que el sintagma dativo es un locativo (p. ej. a todos plogo mucho con esta abenençia) sean equiparables al locativo que encontramos en las colocaciones tipo entrar $N$ en alguien/en un lugar.
} 
sobre los experimentadores sujeto, coincidiendo con la victoria generalizada de la construcción S-V-I con gustar. Esta generalización gradual explicaría por qué entrar en $N$ predominó puntualmente entre el XVII y el XVIII, cuando la construcción S-V-I iba eclipsando a entrar $N$ en alguien pero todavía no se había establecido definitivamente con entrar. Pasado el XIX, entrar en $N$ solo ha podido sobrevivir con aquellos nombres de estado que todavía resultan productivos en la colocación en + sustantivo (y, típicamente, pues, en una CVA con estar). Unido a la existencia de este tipo de colocaciones preposicionales, otro factor que mantiene vivo el esquema entrar en $N$ es que dicho esquema sigue usándose productivamente en colocaciones como entrar en acción y entrar en guerra, esto es, en estructuras con sujeto agentivo donde la construcción S-V-I, al estar asociada con procesos de carácter involuntario, no ha podido generalizarse ${ }^{28}$.

\section{CONCLUSIONES}

Como hemos visto, en periodos anteriores de la lengua, ciertas colocaciones con entrar más sustantivo de estado que hoy se realizan con un experimentador dativo (en el esquema entrarle $N$ ) también aparecían con experimentadores locativos (entrar $N$ en alguien) y con experimentadores sujeto (entrar en $N$ ). Nuestro estudio de corpus sugiere que el esquema dativo ha ido generalizándose desde el Medievo, imponiéndose primero sobre los experimentadores locativos (que predominaron entre el XIV y el XVI) y más tarde sobre los experimentadores sujeto (la realización más frecuente en el XVII y el XVIII).

El auge del esquema entrarle $N$ en el español moderno parece obedecer a dos factores principales: la caída en desuso de las colocaciones tipo en + nombre de estado que forman la base del esquema entrar en $N$, y la extensión de una construcción asociada prototípicamente con procesos físicos o mentales in-

\footnotetext{
${ }^{28}$ Como vimos en la Tabla 1, pese a su victoria sobre los otros dos esquemas, la estructura entrarle $N$ redujo su frecuencia de uso en el XX con relación al siglo anterior. Este descenso se debe a la competencia con otros colocativos incoativos, sobre todo dar, que también participa en la construcción S-V-I (p. ej. a Eva le dieron celos al verlo, esto es 'Eva empezó a tener celos al verlo'). Como se documenta en Alba-Salas (2012b), dar empezó a usarse en las colocaciones incoativas con sustantivos de estado mucho más tarde que entrar y otros verbos (en el XVI o el XVI). Sin embargo, en el XIX dar ya se había convertido en el colocativo más frecuente en dichas estructuras, y en el XX predominaba claramente sobre sus competidores (370-373). Este ascenso vertiginoso se debió a que el dar incoativo tiene una enorme ventaja sobre sus competidores: el hecho de que participa en una alternancia productiva con el dar causativo que encontramos en las colocaciones tipo Miguel le da celos a Eva (esto es, 'Miguel hace tener celos a Eva'). Desde el XVI dar se había convertido en el colocativo causativo más frecuente con los sustantivos de estado (378-381; cfr. Alba-Salas, 2009: 357-359). Gracias a esta alternancia, el dar incoativo - a diferencia de entrar - tiene automáticamente garantizada una presencia más robusta con los sustantivos de estado (para más detalles, véase Alba-Salas, 2012b).
} 
voluntarios (la construcción SUJETO-VERBO-INDIRECTO). El triunfo del esquema entrarle $N$, pues, no constituye un fenómeno aislado, sino que se enmarca dentro de un cambio gramatical que ha afectado a una gran variedad de verbos semánticamente afines a lo largo de la historia del español. Desde este punto de vista, nuestro estudio confirma la conclusión de Alba-Salas (2007: 247, 2009: 361, 2012b: 388) de que las colocaciones están sujetas a procesos sistemáticos de cambio histórico.

\section{BIBLIOGRAFÍA}

Académie française (1986-): Dictionnaire de l'Académie française, 9a ed., <http://atilf.atilf.fr/ academie9.htm> [fecha de consulta: 20/7/2012].

Alba-Salas, Josep (2002): Light Verb Constructions in Romance: A Syntactic Analysis, tesis doctoral inédita, Cornell University, <https://holycross.academia.edu/JosepAlbaSalas>.

Alba-Salas, Josep (2007): "On the Life and Death of a Collocation: A Corpus-Based Diachronic Study of dar miedo/hacer miedo-type Structures in Spanish”, Diachronica, XXIV/2, pp. 207-252.

Alba-Salas, Josep (2009): "Las estructuras tipo meter miedo en diacronía: Más detalles sobre la evolución histórica de las colocaciones causativas", en Andrés Enrique Arias (ed.), Diacronía de las lenguas iberorrománicas: Nuevas aportaciones desde la lingüística de corpus, Madrid, Iberoamericana, pp. 343-364.

Alba-Salas, Josep (2012a): "Colocaciones incoativas con tomar y prender en diacronía”, Revista de Historia de la Lengua Española, VII, pp. 3-38.

Alba-Salas, Josep (2012b): "The Origins and Evolution of Inchoative Collocations with dar in Spanish”, Romance Philology, LXVI, pp. 363-393.

Alba-Salas, Josep (2013a): "Cobrar miedo: Sobre el uso histórico de cobrar con sustantivos que designan cualidades o estados negativos", Scriptum Digital, II, pp. 77-106.

Alba-Salas, Josep (2013b): “De 'recuperar' a 'adquirir': Sobre la evolución histórica de las colocaciones tipo cobrar afecto y cobrar importancia (1200-2000)", Romanische Forschungen, CXXV, pp. 151-193.

Alonso Calvo, Raquel (2009): "Lexicalización y colocaciones: Una introducción a su estudio diacrónico”, Onomázein: Revista de Lingüística, Filología y Traducción, I/19, pp. 33-56.

Alonso Ramos, Margarita (ed.) (1999-): Diccionario de colocaciones del Español, A Coruña, Facultade de Filoloxía, Universidade da Coruña, <http://www.dicesp.com/paginas $>$ [fecha de consulta: 9-15/6/2012].

Alonso Ramos, Margarita (2004): Las construcciones con verbo de apoyo, Madrid, Visor Libros.

Barrajón López, Elisa (2006): Análisis contrastivo locativo-nocional de la complementación de régimen verbal en el español hablado en Alicante: usos espaciales y abstractos de salir y entrar, tesis doctoral inédita, Universidad de Alicante, <http://rua.ua.es/dspace/bitstream/ 10045/11064/1/tesis_barrajon.pdf> [fecha de consulta: 6/2014].

Barðdal, Jóhanna, Thomas Smitherman, Valgerður Bjarnodóttir, Serena Danesi, Gard B. Jenset, y Barbara McGillivray (2012): "Reconstructing Constructional Semantics: The Dative Subject Construction in Old Norse-Icelandic, Latin, Ancient Greek, Old Russian and Old Lithuanian”, Studies in Language, XXXVI/3, pp. 511-547.

Bauer, Brigitte L. M. (1998): "Impersonal Verbs in Italic: Their Development from an IndoEuropean Perspective”, Journal of Indo-European Studies, XXVI/1-2, pp. 91-120.

Beas Teruel, María Angustias (2009): "Transferencia léxica en las colocaciones con hacer y dar en el español de Mallorca desde una perspectiva diacrónica”, en Laura Romero Aguilera y 
Carolina Julià Luna (eds.), Tendencias actuales en la investigación de la lengua, Barcelona, Universitat de Barcelona, pp. 197-205.

Blanco, Marta (1995): "Acerca de algunas lexias complejas del español medieval", Moenia: Revista Lucense de Lingüística y Literatura, I, pp. 411-420.

Bosque, Ignacio (2001): "Sobre el concepto de ‘colocación' y sus límites", LEA: Lingüística Española Actual, XXIII/1, pp. 9-40.

Bosque, Ignacio (dir.) (2004): REDES: Diccionario combinatorio del español contemporáneo, Madrid, SM.

Bustos Plaza, Alberto (2005): Combinaciones verbonominales y lexicalizacioin, Bern, Peter Lang. Cattell, Ray (1984): Composite Predicates in English, Orlando, Academic Press.

Chacoto, Lucília (1998): "Les noms prédicatifs construits avec fazer (faire) au Moyen Âge", Cahiers de l'Institut de Linguistique de Louvain, XXIV/3-4, pp. 127-144.

Chaurand, Jacques (1983): "Les verbes supports en ancien français: donner dans les œuvres de Chrétien de Troyes", Lingvistica Investigationes, VII/1, pp. 11-46.

Cifuentes Honrubia, José Luis, y Jesús Llopis Ganga (1996): Complemento indirecto y complemento de lugar: Estructuras locales de base personal en español, Alicante, Universidad de Alicante.

Corominas, Joan, y José Antonio Pascual (1980-1991): Diccionario crítico etimológico castellano e hispánico, Madrid, Gredos.

Cuervo, Rufino José e Instituto Caro y Cuervo (1998): Diccionario de construcción y régimen de la lengua castellana, Barcelona, Herder.

Davies, Mark (2002): Corpus del Español (100 million words, 1200s-1900s), funded by the US National Endowment for the Humanities, <http://www.corpusdelespanol.org > [fecha de consulta: 6-8/2012, 4-5/2014 y 8/2014].

Dubský, Josef (1962): "Formas descompuestas en el español antiguo", Revista de Filología Española, XLV, pp. 31-48.

Dubský, Josef (1965): "Intercambio de componentes en las formas descompuestas españolas", Bulletin Hispanique, LXVII, pp. 343-352.

Elvira, Javier (2011): "Constructions of Uncontrolled State or Event: The Increase in Productivity of a New Argument Structure in Old Spanish", Constructions and Frames, III/2, pp. 184207.

Eslava Heredia, Cristina (2012): "La alternancia de las preposiciones en/a en verbos de movimiento que denotan penetración en el español de México", Nueva Revista de Filología Hispánica, LX/2, pp. 425-446.

Faulhaber, Charles B., Arthur L-F. Askins, Harvey L. Sharrer y John G. May (1997-): PhiloBiblon, <http://sunsite.berkeley.edu/Philobiblon/phhm.html> [fecha de consulta: 6-8/2012 y 6/2014].

Faulhaber, Charles B., Ángel Gómez Moreno, John Mackenzie, John J. Nitti y Brian Dutton (eds.) (1984): Bibliography of Old Spanish Texts, $3^{\mathrm{a}}$ ed., Madison, Hispanic Seminary of Medieval Studies.

Fernández-Ordóñez, Inés (2001): "Hacia una dialectología histórica. Reflexiones sobre la historia del leísmo, el laísmo y el loísmo", Boletín de la Real Academia Española, LXXX1, pp. 389464.

Fernández-Ordóñez, Inés (2002): "Tras la collatio, o cómo establecer correctamente el error textual", La Corónica, XXX/2, pp. 105-180.

Fernández-Ordóñez, Inés (2006): "La historiografía medieval como fuente de datos lingüísticos. Tradiciones consolidadas y rupturas necesarias", en José de Bustos Tovar y José Luis Girón Alconchel (eds.), Actas del VI Congreso Internacional de Historia de la Lengua española, I, Madrid, Arco/Libros, pp. 1779-1808.

Giry-Schneider, Jacqueline (1987): Les prédicats nominaux en français: L'opérateur 'FAIRE' dans le lexique, Ginebra, Droz. 
Glare, Peter G. W. (ed.) (1996): Oxford Latin Dictionary, Nueva York, Oxford University Press. Goldberg, Adele (1995): Constructions: A Construction Grammar Approach to Argument Structure, Chicago, Chicago University Press.

Goldberg, Adele (2003): "Constructions: A New Theoretical Approach to Language", Trends in Cognitive Sciences, VII/5, pp. 219-224.

Gross, Maurice (1981): "Les bases empiriques de la notion de prédicat sémantique", Langages, XV/63, pp. 7-49.

Houaiss, Antônio (ed.) (2001): Dicionário eletrônico Houaiss da lingua portuguesa, versión 1.0, CD-Rom, Río de Janeiro, Instituto Antônio Houaiss / Editora Objetiva.

Ibarretxe-Antuñano, Iraide (2003): "Entering in Spanish. Conceptual and Semantic Properties of entrar en/a", Annual Review of Cognitive Linguistics, I, pp. 29-58.

Institut d'Estudis Catalans (1985-): DDLC: Diccionari Descriptiu de la Llengua Catalana, <http:/ /dcc.iec.cat/ddlc/index.asp> [fecha de consulta: 7/2012].

Institut d'Estudis Catalans (2007-): DIEC2: Diccionari de la llengua catalana, <http://dlc.iec.cat/ $>$ [fecha de consulta: 7/2012].

Itinera Electronica: Meurant, Alain (ed.) (1998-): Itinera Electronica, <http://potpourri.fltr.ucl.ac.be/itinera/> [fecha de consulta: 6-7/2012 y 12/2013].

Jespersen, Otto (1942): A Modern English Grammar on Historical Principles. Part VI, Morphology, Copenague, Ejnar Munksgaard.

Kabatek, Johannes (2005): "Tradiciones discursivas y cambio lingüístico", Lexis, XXIX/2, pp. 151-177.

La Fauci, Nunzio (1979): Costruzioni con verbo operatore in testi italiani antichi. Esplorazioni sintattiche, Pisa, Giardini.

Latham, Ronald Edward, y David Robert Howlett (eds.) (1975-): Dictionary of Medieval Latin from British Sources, Oxford, Oxford University Press.

Lewis, Charlton T., y Charles Short (1879): A Latin Dictionary, Oxford, Clarendon Press. <http:/ /www.perseus.tufts.edu/hopper/> [fecha de consulta: 6-7/2012 y 12/2013].

Marcello-Nizia, Christiane (1996): "Les verbes supports en diachronie: Le cas du français", Langages, XXX/121, pp. 91-98.

Melis, Chantal (1998): "Sobre la historia sintáctica de gustar", en Claudio García Turza, Fabián González Bachiller y José Javier Mangado Martínez (eds.), Actas del IV Congreso Internacional de Historia de la Lengua Española, La Rioja, Universidad de la Rioja, II, pp. 295-306.

Mendívil Giró, José Luis (1999): Las palabras disgregadas: Sintaxis de las expresiones idiomáticas y los predicados complejos, Zaragoza, Prensas Universitarias de Zaragoza.

Marco, Barbara de (1995): "Verbal Locutions: Their Function in Medieval Miracle Tales", Romance Philology, XLVIII, pp. 416-441.

Moliner, María (1998): Diccionario de uso del español, CD-Rom, versión 2.0, Madrid, Gredos.

Morimoto, Yuko (2001): Los verbos de movimiento, Madrid, Visor.

Paz Afonso, Ana (2013): "Entrar en batalla: Aproximación a las relaciones léxicas entre el verbo entrar y el léxico del siglo XIII", en Emili Casanova y Cesáreo Calvo (eds.), Actes du XXVIe Congrès International de Linguistique et de Philologie Romanes, Berlin, Mouton de Gruyter, pp. 327-337.

Paz Afonso, Ana (2015): "Efectos de prototipicidad y estudio histórico del léxico: análisis semántico de entrar en el s. XIII", en José María García Martín (dir.), Actas del IX Congreso Internacional de Historia de la Lengua Española, II, Madrid/Frankfurt, Iberoamericana/Vervuert, pp. 1549-1564.

Perseus: Crane, Gregory (1992-): Perseus Digital Library Project, Tufts University, <http:// www.perseus.tufts.edu/hopper/> [fecha de consulta: 7/2012 y 4/2014].

Piera, Carlos, y Soledad Varela (1999): "Relaciones entre morfología y sintaxis", en Ignacio Bosque y Violeta Demonte (eds.), Gramática descriptiva de la lengua española, III, Madrid, Espasa-Calpe, pp. 4367-4422. 
Real Academia Española (1996-2006): CREA: Corpus de Referencia del Español Actual, <http:/ /corpus.rae.es/creanet.html> [fecha de consulta: 6/2012].

Real Academia Española (2001): Diccionario de la lengua española, 22 $2^{\mathrm{a}}$ ed., Madrid, EspasaCalpe. <http://www.rae.es/rae.html> [fecha de consulta: 6/2012].

Rivero, María Luisa (2010): "Los verbos psicológicos con experimentante dativo en español y el cambio histórico", Cuadernos de la ALFAL, Nueva Serie, I, pp. 167-193.

Seco, Manuel, Olimpia Andrés y Gabino Ramos (eds.) (2012): Diccionario del español actual, $2^{\mathrm{a}}$ ed., Madrid, Aguilar.

Talmy, Leonard (2000): Toward a Cognitive Semantics, II, Cambridge, MIT Press.

Vázquez Rozas, Victoria, y Elena Rivas (2007): "Un análisis construccionista de la diacronía de gustar", en Iraide Ibarretxe-Antuñano, Carlos Inchaurralde y Jesús Sánchez-García (eds.), Language, Mind, and the Lexicon, Bern, Peter Lang, pp. 143-164.

Villar Díaz, María Belén (2004): Una nueva perspectiva en el análisis de la meronimia: El criterio lexicográfico, tesis doctoral, Universidad de Salamanca.

White, John Tahourdin, y Joseph Esmond Riddle (1872): A Latin-English Dictionary, Boston, Ginn Brothers.

Zingarelli, Nicola, Mario Cannella, Miro Dogliotti, y Luigi Rosiello (eds.) (2010): Lo Zingarelli 2011: Vocabolario della lingua italiana, 12a ed., Bologna, Zanichelli Editore.

Fecha de recepción: 27 de agosto de 2012

Fecha de aceptación: 18 de agosto de 2014 